\title{
Alterações físicas e químicas de um Argissolo pela aplicação de água residuária de bovinocultura
}

\author{
Virgílio J. T. Erthal ${ }^{1}$, Paulo A. Ferreira ${ }^{2}$, Antônio T. de Matos $^{2} \& 0$ dilon G. Pereira ${ }^{3}$
}

\begin{abstract}
RESU MO
Se bem planejada, a disposição de águas residuárias no sistema solo-planta poderá trazer benefícios, tais como fonte de nutrientes e água para as plantas, redução do uso de fertilizantes e de seu potencial poluidor. 0 solo apresenta grande capacidade de decompor ou inativar materiais potencialmente prejudiciais ao ambiente, através de reações químicas e por processos microbiológicos. Com o objetivo de avaliar os efeitos da aplicação da água residuária de bovinocultura (ARB) sobre as propriedades físicas e químicas de um Argissolo Vermelho Eutrófico, realizou-se um experimento utilizando-se quatro taxas de aplicação da ARB $\left(25,50,75\right.$ e $100 \mathrm{~kg} \mathrm{ha}^{-1}$ de K), em condições de lisímetros de drenagem e em ambiente protegido. Avaliaram-se: condutividade el étrica da solução do solo; argila dispersa em água; índice de saturação por sódio; pH; CTC; saturação por bases e os teores de P, K, Ca, M g e Na. O s valores de pH, CTC, saturação por bases e concentrações de $\mathrm{P}, \mathrm{K}, \mathrm{C}$ a e Mg, aumentaram com acréscimos nas taxas de aplicação da ARB, nas camadas superficiais do solo. Não ocorreu salinização do perfil do solo embora a porcentagem de argila dispersa em água tenha aumentado, indicando que a aplicação permanente da ARB pode propiciar riscos de redução da permeabilidade do solo.
\end{abstract}

Palavras-chave: disposição de águas residuárias no solo, fertirrigação, argila dispersa em água

\section{Physical and chemical changes in an Luvisoil by the application of cattle farm wastewater}

\begin{abstract}
When the wastewater disposal in the soil-plant system is well planned, it can provide some benefits, such as a source of nutrients and water for plants and the reduced use of both fertilizers and their pollution potential. The soil has high capacity to decompose or inactivate the material that are potentially harmful to the environment, through chemical reactions and microbiological processes. This study was conducted to evaluate the effects of the application of cattle farm wastewater (ARB) both on physical and chemical properties of an eutrophic Red Luvisoil. The experiment was carried out using four ARB application rates $\left(25,50,75\right.$ and $\left.100 \mathrm{~kg} \mathrm{ha}^{-1} \mathrm{~K}\right)$ and drainage lysimeters under greenhouse conditions. The following variables were evaluated: electrical conductivity of the soil solution; water-dispersed clay; sodium saturation index; $\mathrm{pH}$; $\mathrm{CEC}$; base saturation; and the contents of $\mathrm{P}, \mathrm{K}, \mathrm{Ca}, \mathrm{Mg}$ and $\mathrm{Na}$. According to the results, the increase in ARB application rates provided increments in the $\mathrm{pH}, \mathrm{CEC}$, base saturation as well as in the content of $\mathrm{P}, \mathrm{K}, \mathrm{C}$ a and $\mathrm{Mg}$ in the surface layers. In the soil profile, salinization did not occur, although the percentage of clay dispersed in water increased, indicating that the steadystate ARB application may provide risks for reduction of the permeability of the soil.
\end{abstract}

Key words: soil wastewater disposition, fertirrigation, water-dispersed clay 


\section{INTRODUÇÃO}

A aplicação de águas residuárias no solo é prática comum considerada uma forma de disposição final dessas águas (Feigin et al., 1991). Os efeitos da aplicação de águas residuárias nas propriedades físicas e químicas do solo só se manifestam após longo período de aplicação e dependem das características do solo e do clima.

Ayers \& Westcot (1999) afirmam que a limitação principal do uso de águas residuárias na agricultura é a sua composição química, ou seja, totais de sais dissolvidos, presença de íons tóxicos e a concentração elevada de sódio em relação ao cálcio e magnésio, além da tolerância das culturas. Segundo Pizarro (1990), os sais solúveis contidos nas águas de irrigação podem, em certas condições climáticas, salinizar o solo e modificar a composição iônica no complexo sortivo, alterando as características físicas e químicas do solo, como regime de água, aeração, nutrientes e, consequentemente, o desenvolvimento vegetativo e a produtividade.

As águas residuárias são ricas em macro e micronutrientes e grande parte desses nutrientes é disponibilizada apenas com a mineralização do material orgânico, exceção feita ao potássio e sódio, pois se considera que não estejam associados ao material orgânico e, portanto, não dependem da mineralização para serem disponibilizados no meio (Matos, 2008).

As principais alterações descritas para os solos fertirrigados com águas residuárias se resumem aos efeitos sobre o carbono e nitrogênio totais, atividade microbiana e N-mineral, cálcio e magnésio trocáveis, salinidade, sodicidade e dispersão de argilas (Fonseca et al., 2007a). Em resumo, a disposição de águas residuárias no sistema solo-planta, quando feita sem critérios agronômicos e ambientais, pode causar problemas de contaminação do solo, das águas superficiais e subterrâneas e toxicidade às plantas; por outro lado, se bem planejada esta aplicação pode trazer benefícios, tais como fonte de nutrientes e água para as plantas, redução do uso de fertilizantes e de seu potencial poluidor. Neste sentido se reveste de importância investigar as taxas de aplicação mais adequadas da água residuária em questão, com base nos solutos presentes em maiores concentrações e determinar seus efeitos do ponto de vista agronômico e ambiental.

Objetivou-se, neste trabalho, avaliar os efeitos de quatro taxas de aplicação de água residuária de bovinocultura sobre as características físicas e químicas de um Argissolo Vermelho Eutrófico, cultivado com gramíneas forrageiras em condições de lisímetros de drenagem sob casa de vegetação.

\section{MATERIAL E MÉTODOS}

O trabalho foi conduzido em 21 lisímetros de drenagem de $1,0 \mathrm{~m}$ de largura, $1,40 \mathrm{~m}$ de comprimento e $0,80 \mathrm{~m}$ de profundidade, construídos dentro de uma casa de vegetação, no campus da Universidade Federal de Viçosa, Viçosa, MG, com coordenadas geográficas de $20^{\circ} 45^{\prime}$ de latitude Sul, $42^{\circ} 45^{\prime}$ de longitude Oeste e altitude de $651 \mathrm{~m}$.

Os lisímetros possuíam sistema de drenagem de fundo de caixa ligado a um dispositivo para a coleta do efluente. A espessura do perfil do solo nos lisímetros era de $0,70 \mathrm{~m}$ e o solo utilizado foi coletado no perfil natural de um Argissolo Vermelho Escuro Eutrófico Tb, após destorroamento e peneiramento. $\mathrm{O}$ experimento foi conduzido em esquema de parcelas subdivididas, no delineamento inteiramente casualizado composto por cinco tratamentos (parcelas) com quatro repetições e quatro tempos de amostragem (subparcela) perfazendo o total de 20 unidades experimentais.

Realizou-se a caracterização química e físico-química do solo, Tabela 1, no Laboratório de Física do Solo e Laboratório de Fertilidade do Solo do Departamento de Solos da UFV, segundo metodologias descritas em EMBRAPA (1997).

Com base na recomendação de adubação potássica para manutenção de pastagens (CFSEMG, 1999), os tratamentos se constituíram de quatro taxas de aplicação da água residuária, correspondentes às doses 25, 50, 75 e $100 \mathrm{~kg} \mathrm{ha}^{-1}$ de potássio, por ciclo de cultivo, além de um tratamento com água limpa e adubação mineral, aplicando-se $50 \mathrm{~kg} \mathrm{ha}^{-1} \mathrm{de}$ $\mathrm{N}$ e K, na forma de cloreto de potássio e sulfato de amônio, no início de cada ciclo de cultivo e no início do período experimental foi aplicada adubação fosfatada em todas as parcelas, na dose de $100 \mathrm{~kg} \mathrm{ha}^{-1}$ de $\mathrm{P}_{2} \mathrm{O}_{5}$ na forma de superfosfato simples.

Construiu-se um sistema para preparo e distribuição das misturas de águas referentes aos tratamentos, com cinco reservatórios com capacidade para 250 L, providos de saída controlada por registro e interligados a uma motobomba; essas misturas eram aplicadas manualmente sobre a superfície do solo com o auxílio de uma mangueira equipada com hidrômetro e frequência semanal.

Tabela 1. Características químicas e físicas e químicas do solo

\begin{tabular}{|c|c|c|c|}
\hline Característica & Valor & Característica & Valor \\
\hline Areia grossa (\%) & 18,4 & $\mathrm{Ca}^{2+}\left(\mathrm{cmol}_{\mathrm{c}} \mathrm{dm}^{-3}\right)$ & 2,82 \\
\hline Areia fina (\%) & 9,8 & $\mathrm{Mg}^{2+}\left(\mathrm{cmol}_{\mathrm{c}} \mathrm{dm}^{-3}\right)$ & 0,76 \\
\hline Silte (\%) & 17,0 & $\mathrm{Al}^{3+}\left(\mathrm{cmol}_{\mathrm{c}} \mathrm{dm}^{-3}\right)$ & 0,00 \\
\hline Argila (\%) & 54,8 & $\mathrm{H}+\mathrm{Al}\left(\mathrm{cmol}_{\mathrm{c}} \mathrm{dm}^{-3}\right)$ & 2,31 \\
\hline 1/Ds $\left(\mathrm{kg} \mathrm{dm}^{-3}\right)$ & 1,20 & ${ }^{3 / S B}\left(\mathrm{cmol}_{\mathrm{c}} \mathrm{dm}^{-3}\right)$ & 3,75 \\
\hline${ }^{2} \mathrm{Dp}\left(\mathrm{kg} \mathrm{dm}^{-3}\right)$ & 2,63 & ${ }^{4 / C T C ~ e ~}\left(\mathrm{cmol}_{\mathrm{c}} \mathrm{dm}^{-3}\right)$ & 3,75 \\
\hline Porosidade $\left(\mathrm{dm}^{3} \mathrm{dm}^{-3}\right)$ & 0,54 & ${ }^{5 / C T C ~ p ~}\left(\mathrm{cmol}_{\mathrm{c}} \mathrm{dm}^{-3}\right)$ & 6,06 \\
\hline pH em água & 5,80 & ${ }^{6 / m}(\%)$ & 0,00 \\
\hline $\mathrm{Na}^{+}\left(\mathrm{mg} \mathrm{dm}^{-3}\right)$ & 19,0 & ${ }^{7} \mathrm{~V}(\%)$ & 61,9 \\
\hline$P\left(\mathrm{mg} \mathrm{dm}^{-3}\right)$ & 3,3 & 8/ISNa (\%) & 2,17 \\
\hline $\mathrm{K}^{+}\left(\mathrm{mg} \mathrm{dm}^{-3}\right)$ & 38,7 & ${ }^{9} / \mathrm{P}-\operatorname{rem}\left(\mathrm{mg} \mathrm{L}^{-1}\right)$ & 26,3 \\
\hline
\end{tabular}

1/Densidade do solo; ${ }^{2 / D e n s i d a d e ~ d e ~ p a r t i ́ c u l a s ; ~}{ }^{3 / S}$ Soma de bases trocáveis; ${ }^{4 / C}$ apacidade de troca

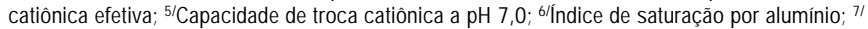
Índice de saturação por bases; ${ }^{8 /}$ Índice de saturação de sódio; ${ }^{9 /}$ Fósforo remanescente

A água residuária utilizada foi coletada no estábulo do Setor de Bovinocultura de Leite do Departamento de Zootecnia da UFV, transportada e armazenada em um tanque com capacidade para $3000 \mathrm{~L}$, montado sobre uma carreta, a qual era estacionada ao lado da estação lisimétrica. Coletaram-se, para a caracterização do efluente, amostras no início de cada ciclo de cultivo das forrageiras, quando eram analisadas as seguintes características: Sólidos totais; DQO; C-total; N-total; P-total; Ca; Mg; K; Na; Zn; Cu; pH; condutividade elétrica (CE) e relação de adsorção de sódio 
(RAS). As análises, realizadas no Laboratório de Matéria Orgânica e Resíduos do Departamento de Solos da UFV, se basearam em metodologias recomendadas pela APHA (1995); os resultados das análises estão apresentados na Tabela 2.

A instalação do experimento ocorreu na primeira quinzena do mês de outubro de 2006, quando as mudas de capimTifton 85 foram transplantadas; após setenta dias se iniciaram os tratamentos com as diferentes misturas de águas. No total, foram três ciclos de produção (cortes) do capim-Tifton 85 e um ciclo de Tifton 85 em consórcio com aveia-preta, sobressemeada nas entrelinhas, na densidade correspondente a $70 \mathrm{~kg} \mathrm{ha}^{-1}$ de sementes.

Realizaram-se as determinações das propriedades físicas e químicas do solo em cinco etapas, sendo uma inicial e as outras após cada ciclo de produção das forrageiras; as amostras de solo foram retiradas, em todos os lisímetros, nas faixas de profundidade de $0-10$ e $10-25 \mathrm{~cm}$; com as amostras simples de cada parcela de um mesmo tratamento, obtiveram-se amostras compostas por tratamento e profundidade.

Tabela 2. Características da água residuária de bovinocultura (ARB)

\begin{tabular}{|c|c|c|c|c|c|c|c|}
\hline \multirow{2}{*}{ Ciclo } & $\begin{array}{l}\text { Sólidos } \\
\text { Totais }\end{array}$ & DQO & C-Total & N-Total & $P^{*}$ & $K^{*}$ & $\mathrm{Ca}^{*}$ \\
\hline & \multicolumn{7}{|c|}{$\mathrm{mg} \mathrm{L}^{-1}$} \\
\hline I & 13045,0 & 50487,0 & 2845,6 & 1162,99 & 289,25 & 507,92 & 149,75 \\
\hline$\|$ & 6728,0 & 6768,0 & 1113,5 & 591,03 & 114,00 & 390,00 & 191,61 \\
\hline III & 5110,0 & 5076,4 & 742,3 & 522,57 & 65,14 & 280,00 & 109,12 \\
\hline IV & 5085,0 & 3826,0 & 685,1 & 512,25 & 58,80 & 270,00 & 42,53 \\
\hline Média & 7492,0 & 16539,4 & 1346,6 & 697,21 & 131,80 & 361,98 & 123,25 \\
\hline CV (\%) & 50,47 & 137,03 & 75,54 & 44,82 & 81,81 & 30,79 & 56,84 \\
\hline \multirow{2}{*}{ Ciclo } & $\mathbf{M g}^{*}$ & $\mathrm{Na}^{*}$ & $\mathrm{Zn}^{*}$ & $\mathrm{Cu}^{*}$ & \multirow[t]{2}{*}{$\mathrm{pH}$} & CEa & RAS \\
\hline & \multicolumn{4}{|c|}{$\mathrm{mg} \mathrm{L}^{-1}$} & & dS $m^{-1}$ & $\left(\mathrm{mmol}_{\mathrm{c}} \mathrm{L}^{-1}\right)^{0.5}$ \\
\hline I & 129,75 & 145,97 & 4,20 & 2,88 & 7,12 & 3,99 & 2,11 \\
\hline \|I & 0,00 & 72,00 & 4,47 & 2,30 & 8,39 & 3,96 & 0,45 \\
\hline III & 0,00 & 78,00 & 1,85 & 0,06 & 7,89 & 4,64 & 0,65 \\
\hline IV & 0,00 & 67,40 & 1,23 & 0,05 & 7,95 & 4,45 & 0,90 \\
\hline Média & 32,44 & 90,84 & 2,94 & 1,32 & 7,84 & 4,26 & 1,03 \\
\hline CV (\%) & 199,98 & 40,74 & 55,69 & 112,32 & 6,73 & 7,94 & 72,31 \\
\hline
\end{tabular}

CEa - condutividade elétrica da água; CV - coeficiente de variação; * teores totais

As amostras foram identificadas e encaminhadas aos Laboratórios de Física e Fertilidade de Solos do Departamento de Solos da UFV, para realização das análises, de acordo com metodologias descritas em EMBRAPA (1997). Analisaramse as seguintes características: condutividade elétrica do extrato da pasta do solo saturado $\left(\mathrm{CE}_{\mathrm{es}}\right)$; argila dispersa em água (ADA); índice de saturação por sódio (ISNa); pH; CTC; saturação por bases e teores de $\mathrm{P}, \mathrm{K}, \mathrm{Ca}, \mathrm{Mg}$ e $\mathrm{Na}$.

A análise estatística dos dados foi feita por meio de regressão das características avaliadas em função das taxas de aplicação e dos tempos de amostragem, para cada faixa de profundidade, utilizando-se a metodologia de superfície de resposta, a partir dos quais se fizeram cortes para representação gráfica, fixando-se as taxas de aplicação e se incluindo o tratamento testemunha como referência. Os modelos foram escolhidos com base na significância dos coeficientes de regressão, utilizando-se o teste "t” adotando-se $\alpha$ de até
$10 \%$, no fenômeno em estudo e no coeficiente de determinação $\left(\mathrm{R}^{2}\right)$ calculado pela Eq. 1, para dados sem repetição.

$$
\mathrm{R}^{2}=\frac{\mathrm{SQRg}}{\mathrm{SQTot}}
$$

em que:

SQRg - soma de quadrados da regressão

SQTot - soma de quadrados total

\section{RESULTADOS E DISCUSSÃO}

\section{Aporte de nutrientes}

Com base nas concentrações de nutrientes presentes na ARB no início de cada ciclo e nos volumes aplicados por ciclo, estimou-se o aporte de nutrientes aos lisímetros pela água residuária (Tabela 3). Nessa estimativa se consideraram apenas os teores totais de cada nutriente, não se levando em consideração a forma como os nutrientes se encontravam no efluente.

Ressalta-se que todos os resultados encontrados para as diferentes variáveis estudadas foram analisados em relação às doses de $\mathrm{K}$ na ARB tomando-se como referência as taxas de aplicação utilizadas nos tratamentos.

Tabela 3. A porte de nutrientes via água residuária de bovinocultura (ARB) durante 0 experimento

\begin{tabular}{|c|c|c|c|c|c|c|c|c|}
\hline \multirow{2}{*}{ Ciclo } & \multirow{2}{*}{ Tratam } & \multirow{2}{*}{$\begin{array}{c}\text { Volume } \\
\text { ARB }\end{array}$} & $\mathrm{N}$-total & $\mathbf{P}$ & K & $\mathrm{Ca}$ & Mg & $\mathrm{Na}$ \\
\hline & & & \multicolumn{6}{|c|}{ kg ha-1 } \\
\hline \multirow{4}{*}{ I } & 25 & 7,0 & 58,1 & 14,5 & 25,4 & 7,5 & 6,5 & 7,3 \\
\hline & 50 & 14,0 & 116,3 & 28,9 & 50,8 & 15,0 & 13,0 & 14,6 \\
\hline & 75 & 21,0 & 174,4 & 43,4 & 76,2 & 22,5 & 19,5 & 21,9 \\
\hline & 100 & 28,0 & 232,6 & 57,9 & 101,6 & 30,0 & 26,0 & 29,2 \\
\hline \multirow{4}{*}{ II } & 25 & 9,0 & 38,0 & 7,3 & 25,1 & 12,3 & 0,0 & 4,6 \\
\hline & 50 & 18,0 & 76,0 & 14,7 & 50,1 & 24,6 & 0,0 & 9,3 \\
\hline & 75 & 27,0 & 114,0 & 22,0 & 75,2 & 37,0 & 0,0 & 13,9 \\
\hline & 100 & 36,0 & 152,0 & 29,3 & 100,3 & 49,3 & 0,0 & 18,5 \\
\hline \multirow{4}{*}{ III } & 25 & 12,5 & 46,7 & 5,8 & 25,0 & 9,7 & 0,0 & 7,0 \\
\hline & 50 & 25,0 & 93,3 & 11,6 & 50,0 & 19,5 & 0,0 & 13,9 \\
\hline & 75 & 37,5 & 140,0 & 17,4 & 75,0 & 29,2 & 0,0 & 20,9 \\
\hline & 100 & 50,0 & 186,6 & 23,3 & 100,0 & 39,0 & 0,0 & 27,9 \\
\hline \multirow{4}{*}{ IV } & 25 & 13,0 & 47,6 & 5,5 & 25,1 & 3,9 & 0,0 & 6,3 \\
\hline & 50 & 26,0 & 95,1 & 10,9 & 50,1 & 7,9 & 0,0 & 12,5 \\
\hline & 75 & 38,0 & 142,7 & 16,4 & 75,2 & 11,8 & 0,0 & 18,8 \\
\hline & 100 & 52,0 & 190,3 & 21,8 & 100,3 & 15,8 & 0,0 & 25,0 \\
\hline \multirow{4}{*}{ Total } & 25 & 41,5 & 190,4 & 33,1 & 100,5 & 33,5 & 6,5 & 25,1 \\
\hline & 50 & 83,0 & 380,7 & 66,1 & 201,1 & 67,0 & 13,0 & 50,3 \\
\hline & 75 & 123,0 & 571,1 & 99,2 & 301,6 & 100,5 & 19,5 & 75,4 \\
\hline & 100 & 166,0 & 761,5 & 132,3 & 402,2 & 134,0 & 26,0 & 100,6 \\
\hline
\end{tabular}

\section{Efeitos das taxas de aplicação e do tempo por faixa de profundidade}

Apresentam-se, na Tabela 4, os modelos de superfície de resposta ajustados para as características do solo, em função da taxa de aplicação da ARB e do tempo, para cada faixa de profundidade. 
Tabela 4. Modelos de superfície de resposta ajustados às características do solo em função da taxa de aplicação da ARB (x) e do tempo (z) por faixa de profundidade

\begin{tabular}{|c|c|c|}
\hline Prof. (cm) & Equação ajustada & $\mathbf{R}^{2}$ \\
\hline \multicolumn{3}{|c|}{$\mathrm{pH}$} \\
\hline $0-10$ & $\hat{y}=5,642+0,00906^{9 \%} x-0,000051^{16,5 \%} x^{2}-0,00112^{33 \%} z+0,0000151^{4,8 \%} z^{2}$ & 0,845 \\
\hline $10-25$ & $\hat{y}=5,413+0,00194^{0,35 \%} x+0,00689^{0,01 \%} z-0,0000215^{0,02 \%} z^{2}$ & 0,767 \\
\hline \multicolumn{3}{|c|}{ COT $($ dag kg-1) } \\
\hline $0-10$ & $\hat{y}=0,8128-0,00133^{36,4 \%} x+0,00003^{16,4 \%} x^{2}+0,0018^{12,0 \%} z-0,000006^{12,4 \%} z^{2}$ & 0,596 \\
\hline $10-25$ & $\hat{y}=0,9873+0,00035^{37,3 \%} x-0,000328^{23,6 \%} z$ & 0,048 \\
\hline \multicolumn{3}{|c|}{$\mathrm{P}\left(\mathrm{mg} \mathrm{dm}^{-3}\right)$} \\
\hline $0-10$ & $\hat{y}=1,194+0,01669^{12,7 \%} x+0,03438^{0,01 \%} z-0,0002219^{1,6 \%} x z$ & 0,862 \\
\hline $10-25$ & $\hat{y}=7,308-0,0945^{3,4 \%} x+0,00062^{6,0 \%} x^{2}-0,00391^{14,0 \%} z$ & 0,408 \\
\hline \multicolumn{3}{|c|}{$\mathrm{K}\left(\mathrm{mg} \mathrm{dm}^{-3}\right)$} \\
\hline $0-10$ & $\hat{y}=16,91+0,4440^{24,0 \%} x-0,0053^{13,2 \%} x^{2}+0,2053^{3,6 \%} z+0,00401^{1,1 \%} x z$ & 0,925 \\
\hline $10-25$ & $\hat{y}=28,58+0,9845^{1,8 \%} x-0,00750^{2,1 \%} x^{2}+0,6035^{0,2 \%} z-0,002038^{0,2 \%} z^{2}$ & 0,646 \\
\hline \multicolumn{3}{|c|}{$\mathrm{Ca}\left(\mathrm{cmol}_{\mathrm{c}} \mathrm{dm}^{-3}\right)$} \\
\hline $0-10$ & $\hat{y}=2,717-0,00191^{38,4 \%} x-0,000026^{30,6 \%} x^{2}-0,01762^{0,01 \%} z+0,000099^{0,01 \%} z^{2}$ & 0,986 \\
\hline $10-25$ & $\hat{y}=2,732+0,0211^{4,6 \%} x-0,000201^{2,4 \%} x^{2}-0,02785^{0,01 \%} z+0,000138^{0,01 \%} z^{2}$ & 0,967 \\
\hline \multicolumn{3}{|c|}{$\mathrm{Mg}\left(\mathrm{cmol}_{\mathrm{c}} \mathrm{dm}^{-3}\right)$} \\
\hline $0-10$ & $\hat{y}=0,7103-0,0024^{25,8 \%} x+0,000023^{21,6 \%} x^{2}-0,005548^{0,1 \%} z+0,000032^{0,01 \%} z^{2}$ & 0,959 \\
\hline $10-25$ & $\hat{y}=0,3816-0,00731^{10,3 \%} x+0,000067^{0,1 \%} x^{2}-0,00047^{29,0 \%} z+0,0000075^{1,0 \%} z^{2}$ & 0,933 \\
\hline \multicolumn{3}{|c|}{ CTC $\left(\mathrm{cmol}_{\mathrm{c}} \mathrm{dm}^{-3}\right)$} \\
\hline $0-10$ & $\hat{y}=3,549-0,00338^{2 \%} x-0,0229^{0,001 \%} z+0,0001366^{0,001 \%} z^{2}$ & 0,987 \\
\hline $10-25$ & $\hat{y}=3,202+0,01697^{8,7 \%} x-0,000154^{6,1 \%} x^{2}-0,0271^{0,001 \%} z+0,000143^{0,001 \%} z^{2}$ & 0,973 \\
\hline \multicolumn{3}{|c|}{$\mathrm{V}(\%)$} \\
\hline $0-10$ & $\hat{y}=56,51+0,103^{31,3 \%} x-0,00085^{30,5 \%} x^{2}+0,0604^{0,09 \%} z$ & 0,572 \\
\hline $10-25$ & $\hat{y}=36,81+0,4011^{4,5 \%} x-0,00269^{7,1 \%} x^{2}+0,2286^{1,0 \%} z-0,000688^{1,7 \%} z^{2}$ & 0,564 \\
\hline \multicolumn{3}{|c|}{ CE $\left(\mathrm{dS} \mathrm{m}^{-1}\right)$} \\
\hline $0-10$ & $\hat{y}=0,0541+0,00016^{44,2 \%} x+0,00778^{0,34 \%} z-0,0000199^{1,4 \%} z^{2}$ & 0,673 \\
\hline $10-25$ & $\hat{y}=0,241+0,00053^{23,1 \%} x+0,00507^{0,3 \%} z-0,0000139^{1,0 \%} z^{2}$ & 0,620 \\
\hline \multicolumn{3}{|c|}{$\mathrm{Na}\left(\mathrm{mg} \mathrm{dm}^{-3}\right)$} \\
\hline $0-10$ & $\hat{y}=14,795+0,1705^{14,7 \%} x-0,0003^{40,5 \%} x^{2}-0,0613^{16,5 \%} z+0,00058^{0,8 \%} z^{2}$ & 0,918 \\
\hline $10-25$ & $\hat{y}=30,26-0,1258^{25,8 \%} x-0,0001^{47,2 \%} x^{2}-0,1912^{1,4 \%} z+0,000663^{0,8 \%} z^{2}+0,00178^{0,2 \%} x z$ & 0,918 \\
\hline \multicolumn{3}{|c|}{ ISNa (\%) } \\
\hline $0-10$ & $\hat{y}=1,993+0,0206^{0,01 \%} x+0,01571^{3,9 \%} z-0,0000657^{1,7 \%} z^{2}$ & 0,778 \\
\hline $10-25$ & $\hat{y}=3,251-0,0130^{14,2 \%} x+0,00918^{23,4 \%} z-0,0000754^{3,6 \%} z^{2}+0,000206^{1,0 \%} x z$ & 0,646 \\
\hline \multicolumn{3}{|c|}{ ADA (\%) } \\
\hline $0-10$ & $\hat{y}=45,077-0,0298^{9,3 \%} x-0,01522^{6,9 \%} z+0,000291^{2,9 \%} z^{2}$ & 0,337 \\
\hline $10-25$ & $\hat{y}=41,172-0,04646^{35,3 \%} x+0,00070^{22,3 \%} x^{2}+0,01568^{22,8 \%} z-0,000293^{17,2 \%} x z$ & 0,134 \\
\hline
\end{tabular}

Com base na significância dos coeficientes de regressão apresentados, verifica-se que o efeito do fator tratamento (taxas de aplicação) foi, em geral, menor que o fator tempo sobre o comportamento das características avaliadas; face a esses resultados, deu-se preferência à representação gráfica a partir das equações ajustadas em função do tempo, fixando-se as doses de $\mathrm{K}$ na ARB, por faixa de profundidade; optou-se, também, por incluir o tratamento testemunha como referência para o comportamento das variáveis.

A aplicação de ARB proporcionou aumento nos valores de $\mathrm{pH}$ do solo ao longo do período experimental, em relação ao tratamento testemunha, de forma mais pronunciada na camada 0-10 cm e ligeiro aumento na camada 10-25 cm, conforme se observa nas Figura 1A e B.

A adição de matéria orgânica tem apresentado efeitos muitas vezes contraditórios sobre o pH do solo. De acordo com Bouwer (2000), em solos que receberam águas residuárias pode haver diminuição no valor de $\mathrm{pH}$ em virtude da degradação dos resíduos biodegradáveis que propicia a pro- dução de $\mathrm{CO}_{2}$ e ácidos orgânicos. Queiroz et al. (2004) notaram redução do $\mathrm{pH}$ nas parcelas de solo que receberam água residuária de suinocultura. Por outro lado, tem-se observado incrementos no valor de $\mathrm{pH}$ do solo quando fertirrigados com águas residuárias em sistemas agrícolas de pastagens (Quin \& Woods, 1978) e florestas (Cromer et al., 1984). Acreditase que, no presente trabalho, o aumento observado no $\mathrm{pH}$ do solo pode ser atribuído a: (i) pH básico do efluente (Stewart et al., 1990); (ii) adição de cátions trocáveis e ânions pelo efluente (Falkiner \& Smith, 1997) e (iii) adição de resíduos orgânicos ao solo seguidos da descarboxilação e desaminação, processos consumidores de prótons (Yan et al., 1996).

Após o período de aplicação da ARB o solo apresentou baixas concentrações de carbono orgânico total, de acordo com a CFSEMG (1999), nas profundidades avaliadas (Figura 1C e D), indicando baixos teores de matéria orgânica do solo (MOS). Observa-se que não ocorreu acúmulo de matéria orgânica nas camadas 0-10 e 10-20 cm com o tempo de aplicação. 
Decréscimos na concentração de COT foram relatados em diversos outros estudos sendo atribuídos aos seguintes fatores: (i) predominância de $\mathrm{N}$ na forma mineral (Feigin at al., 1991); (ii) manutenção de condições ideais para a mineralização da matéria orgânica como umidade (Myers et al., 1982); temperatura (Artiola \& Pepper, 1992); aeração (Stanford \& Smith, 1972); baixa relação C:N da água residuária (Fonseca et al., 2007b) e (iii) incremento da atividade microbiana, estimulando a decomposição da MOS (Barton et al., 2005; Fonseca et al., 2005) associado ao efeito "priming”. De acordo com Stevenson (1986), o efeito "priming” consiste em um estímulo normalmente positivo, que ocasiona incremento na taxa de decomposição da MOS devido ao crescimento extenso e vigoroso da população microbiana quando material rico em energia é adicionado ao sistema e, subsequentemente, microrganismos produzem enzimas que atacam a MOS. A magnitude de diminuição da concentração de MOS depende principalmente do tamanho e da atividade da microflora. Por outro lado, au-
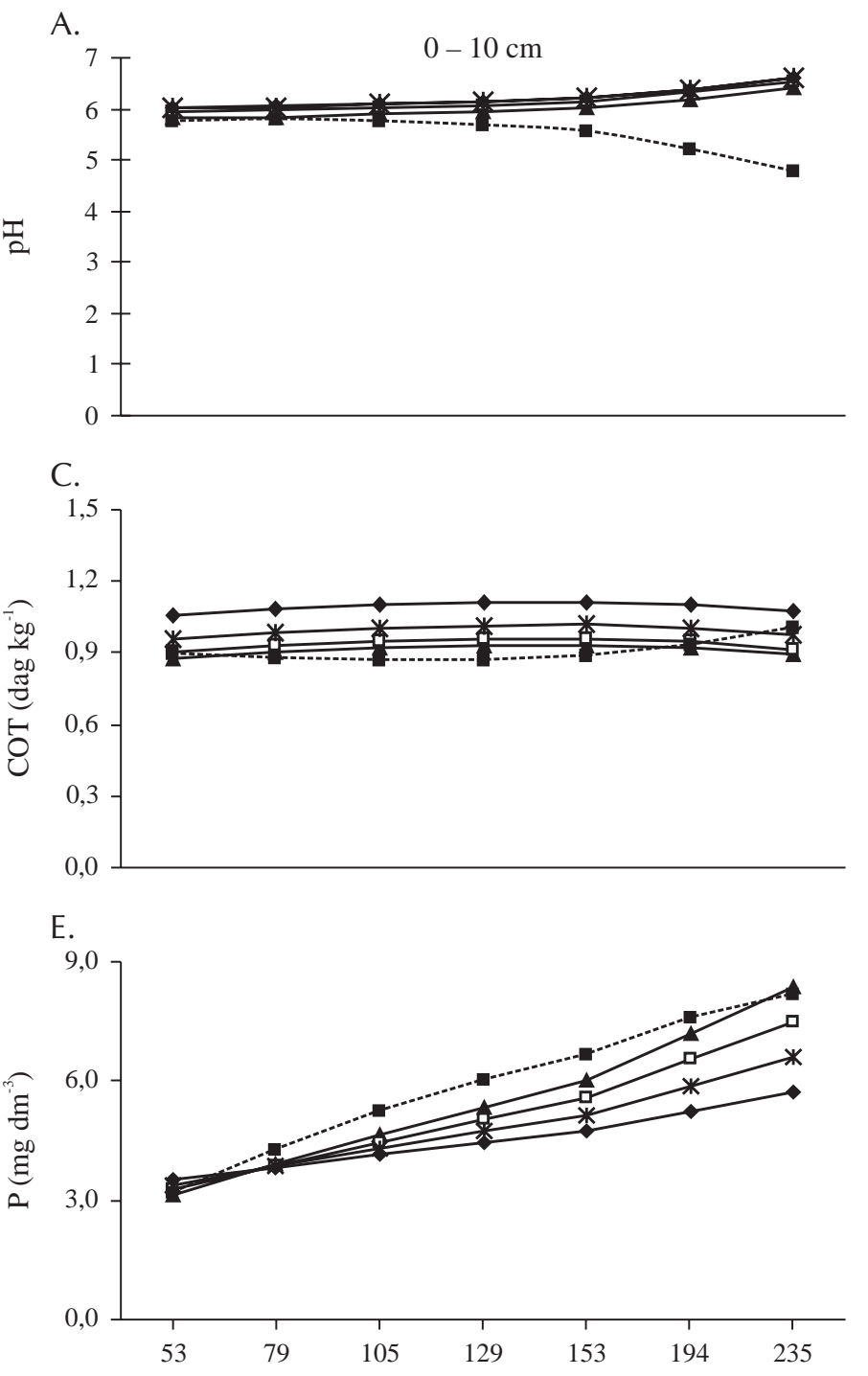

mentos nos teores de COT no solo devido à aplicação de águas residuárias têm sido observados sobretudo em estudos de longa duração, como relatados por Quin \& Woods (1978), Friedel et al. (2000) e Ramirez-Ruentes et al. (2002).

A concentração de $\mathrm{P}$ disponível no solo aumentou apenas na camada superficial $(0-10 \mathrm{~cm})$, para todos os tratamentos (Figura 1E e F) comportamento este devido à baixa mobilidade do P no perfil do solo. Destaca-se o fato do tratamento correspondente à menor dose de $\mathrm{K}\left(25 \mathrm{~kg} \mathrm{ha}^{-1}\right)$, ter apresentado, em geral, a maior concentração de $\mathrm{P}$ disponível, em ambas as profundidades, o que poderia ser atribuído, em parte, ao menor aporte de matéria orgânica, reduzindo a possibilidade de quelação e/ou complexação do P-disponível. De acordo com a CFSEMG (1999), os valores médios de $\mathrm{P}$ disponível encontrados em ambas as faixas de profundidade são considerados baixos, indicando que a utilização da ARB como fonte de P é parcial, necessitando de complementação na forma mineral.

B.

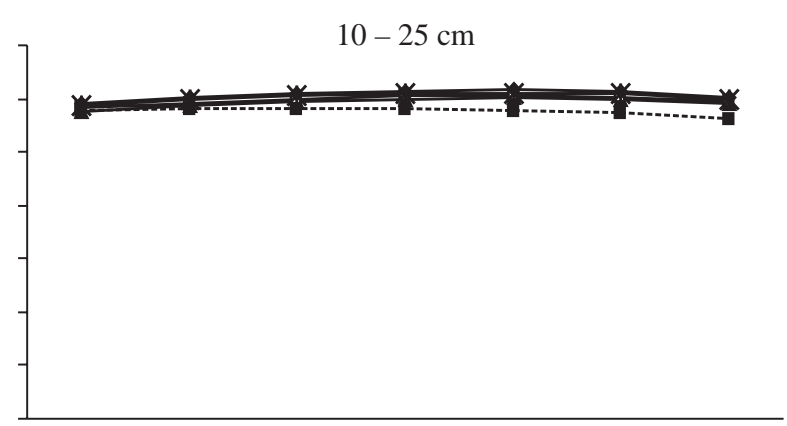

D.

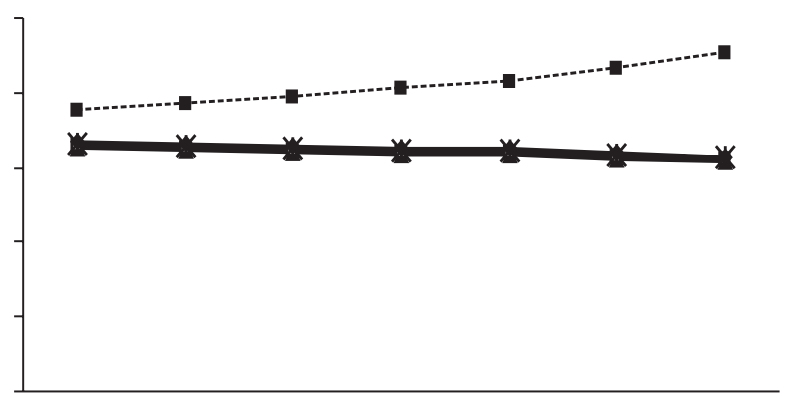

F.

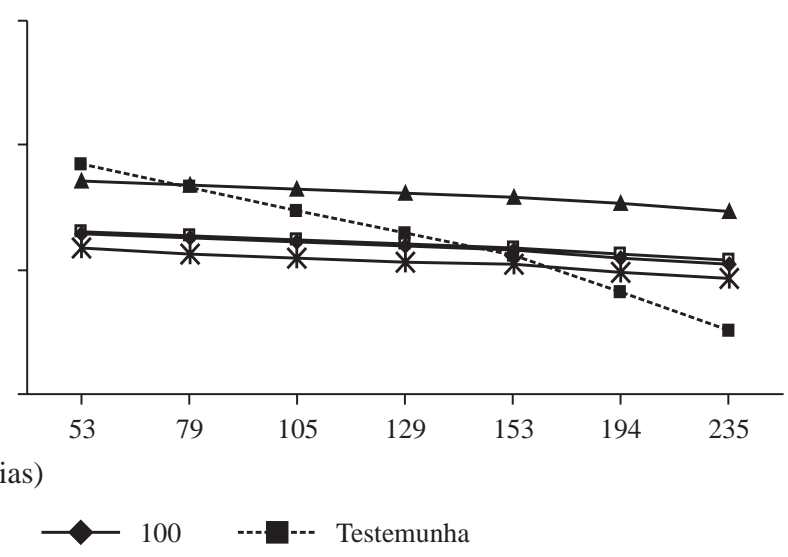

Figura 1. Valores de pH e concentrações de COT e P disponível estimadas em função do tempo, tratamento e faixa de profundidade 
Fonseca et al. (2007a) afirmam que o aporte de $\mathrm{P}$ para o solo, em razão da aplicação via águas residuárias, é baixo; os incrementos de P disponível após a aplicação do efluente são observados nas camadas superficiais (Quin \& Woods, 1978; Queiroz et al., 2004; Medeiros et al., 2005) e camadas subsuperficiais, mais pronunciadas em experimentos com mais de cinco anos de duração (Al-Nakshabandi et al., 1997; Mohammad \& Mazahreh, 2003; Wang et al., 2003).

$\mathrm{O}$ fato do $\mathrm{P}$ na testemunha ter aumentado em $0-10 \mathrm{~cm}$ e diminuído em 10-25 cm, ao longo do tempo, pode ser devido à baixa mobilidade deste nutriente no perfil, visto que foi realizada aplicação de fonte de P solúvel na camada superficial, no início do experimento.

A concentração de K trocável aumentou consideravelmente nos primeiros $10 \mathrm{~cm}$ de profundidade do solo, com todas as taxas de aplicação de ARB, ao longo do período experimental (Figura 2A e B), atingindo valores considerados bons, segundo a CFSEMG (1999), até essa profundidade.
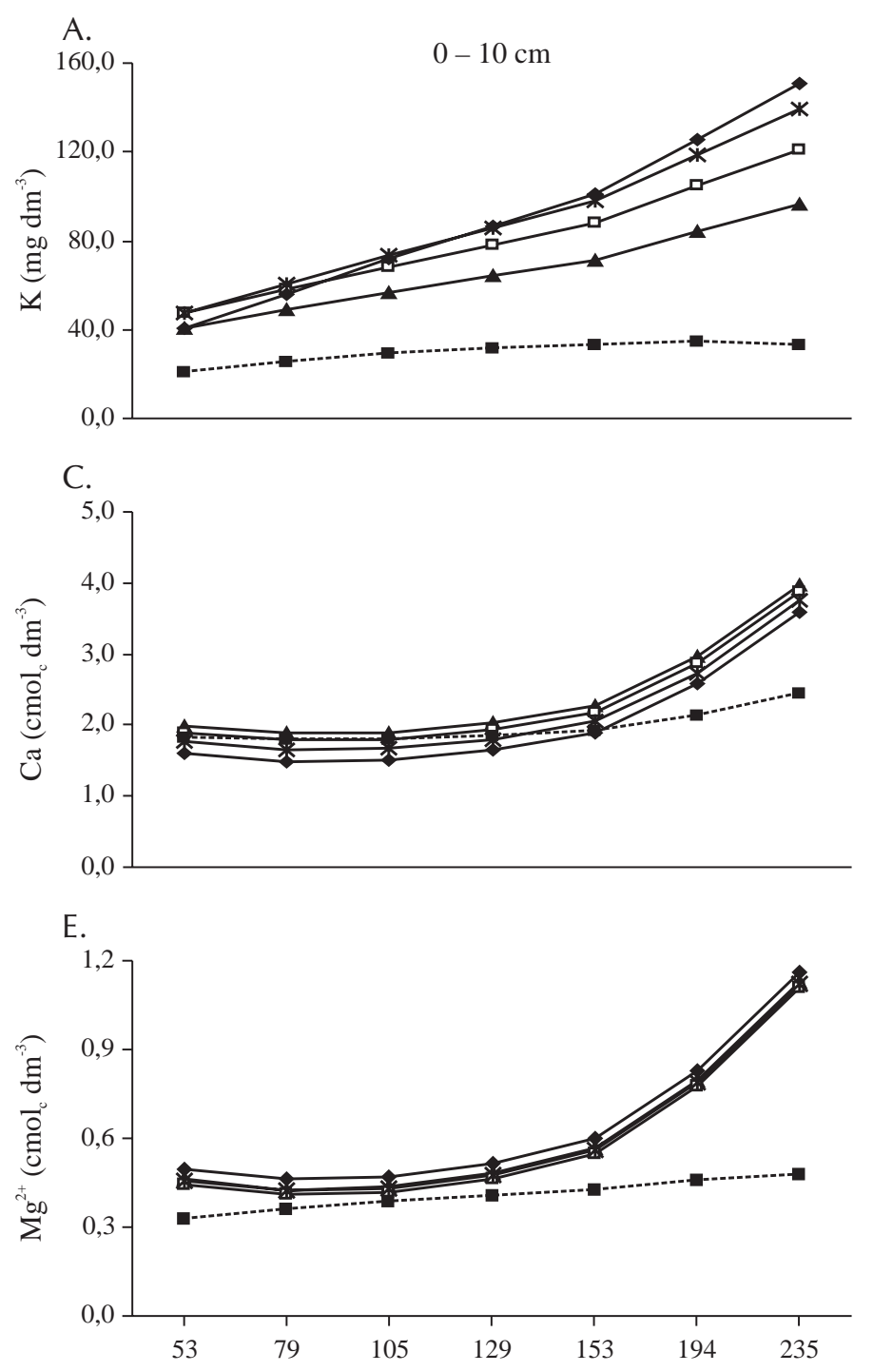

Matos et al. (2005), ao avaliarem os efeitos da aplicação de águas residuárias da lavagem e despolpa dos frutos do cafeeiro (ARC) nas características químicas do solo de rampas de tratamento cultivadas com diferentes espécies forrageiras, também observaram que as maiores concentrações de potássio ocorreram na camada de 0 a $10 \mathrm{~cm}$ de profundidade. Os autores argumentaram que, apesar do potássio ser considerado um cátion relativamente móvel no solo, o pequeno período de aplicação de ARC, coincidente com o período de poucas chuvas, mostrou-se insuficiente para proporcionar maior lixiviação desse cátion no perfil do solo; raciocínio análogo pode ser utilizado neste trabalho visto que o experimento foi conduzido em ambiente protegido e as lâminas de irrigação aplicadas proporcionaram baixa lixiviação de cátions no solo.

É necessário ressaltar que o aumento na concentração de $\mathrm{K}$ trocável na camada superior do solo é forte indicativo de que o teor deste cátion no solo deve ser monitorado e usado como referência na definição de doses a serem aplicadas de ARB.

B.

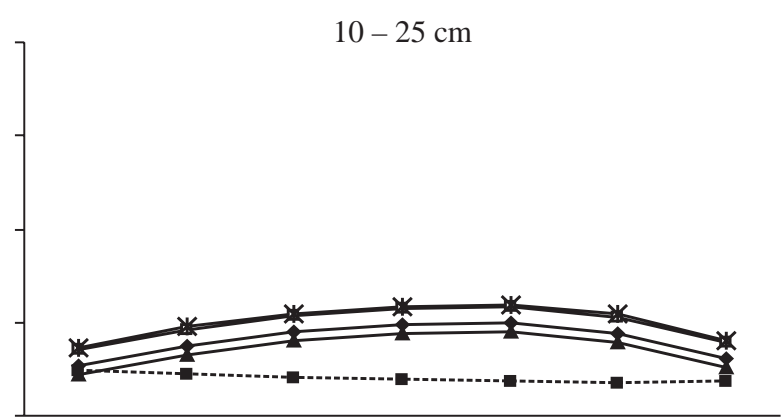

D.

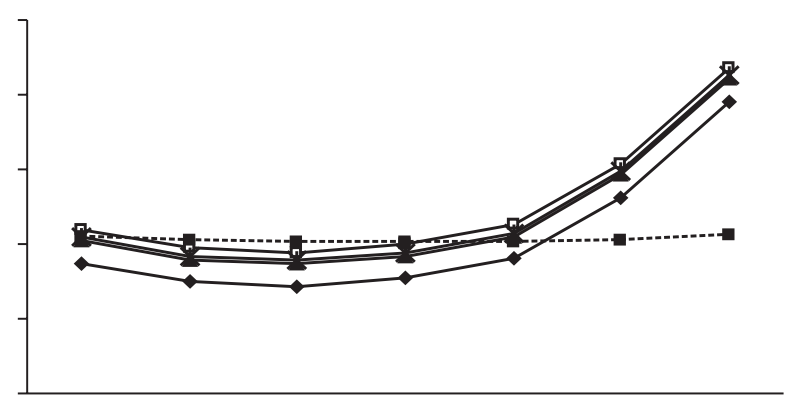

F.

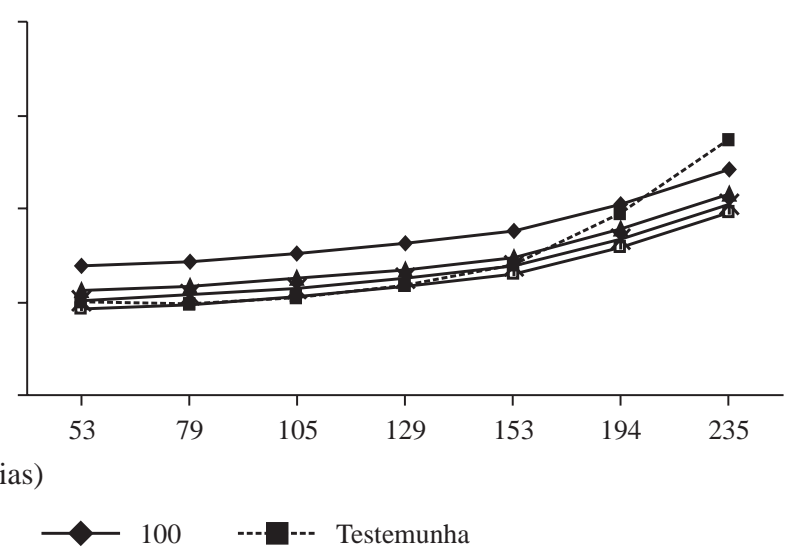

Figura 2. Concentrações de $\mathrm{K}^{+}, \mathrm{Ca}^{2+}$ e $\mathrm{Mg}^{2+}$ do solo, estimadas em função do tempo, tratamento e faixa de profundidade 
Os resultados de pesquisas envolvendo o $\mathrm{K}^{+}$em águas residuárias são, às vezes, contraditórios. Johns \& McConchie (1994) não notaram alteração no teor deste íon no solo ao aplicarem efluente secundário de esgoto doméstico na fertirrigação de bananeiras, embora se deva ressaltar que o esgoto doméstico é fonte insuficiente de K para a cultura da bananeira; por outro lado, incrementos na concentração de $\mathrm{K}^{+}$foram observados em solos com exploração florestal (Cromer et al., 1984; Falkiner \& Smith, 1997), cultivados com berinjela (Al-Nakshabandi et al., 1997), gramíneas (Queiroz et al., 2004) e cafeeiro (Medeiros et al., 2005), quando da aplicação de outras águas residuárias; já Stewart et al. (1990) verificaram que a aplicação de efluente de esgoto tratado (EET) causou decréscimos na concentração de $\mathrm{K}^{+}$em virtude do incremento da concentração de $\mathrm{Na}^{+}$no solo, favorecendo a dessorção e lixiviação de K no solo.

Os tratamentos que receberam ARB apresentaram concentrações elevadas e crescentes de cálcio trocável (Figura 2C e D). De acordo com a CFSEMG (1999), esses valores caracterizam um solo de boa fertilidade em relação ao cálcio; observa-se, também, que os tratamentos com ARB proporcionaram teores de $\mathrm{Ca}^{2+}$ superiores, quando comparados com a testemunha, porém não se observa tendência de lixiviação, visto que a concentração não aumentou com a profundidade. O acúmulo de cálcio verificado ao longo do tempo pode ser explicado pelo aumento do aporte de $\mathrm{Ca}^{2+}$, propiciado pela ARB a partir do segundo ciclo (Tabela 3), sendo superior à absorção promovida pelas forrageiras e em virtude da liberação desse cátion pela mineralização da matéria orgânica retida nesta faixa, a partir dos 153 dias.

Em relação ao magnésio trocável (Figura 2E e F), nos primeiros $10 \mathrm{~cm}$ de profundidade do solo os tratamentos que receberam ARB apresentaram concentrações de $\mathrm{Mg}^{2+}$ superiores à testemunha em todo o período experimental, notadamente a partir de 150 dias, com valores finais acima de $0,90 \mathrm{cmol}_{\mathrm{C}} \mathrm{dm}^{-3}$.

As concentrações de $\mathrm{Mg}^{2+}$ aumentaram com o tempo de aplicação da ARB para todos os tratamentos, caracterizando um comportamento semelhante ao apresentado pelo cálcio, embora o aporte de $\mathrm{Mg}^{2+}$ proporcionado pela ARB ao longo do período tenha sido bem menor (Tabela 3); tal fato pode ser devido à intensa liberação deste íon com a mineralização da matéria orgânica retida nessa faixa do solo com o passar do tempo, e à alta concentração de potássio, conhecido competidor com o magnésio na absorção pelas plantas, causando baixa absorção desse nutriente e consequente acúmulo no solo. Mônaco et al. (2007), ao avaliarem os efeitos da fertirrigação do cafeeiro com diferentes doses de água residuária da lavagem e descascamento de seus frutos (ARC), observaram o mesmo comportamento, visto que aquela água é muito rica em $\mathrm{K}$.

De acordo com as Figura $3 \mathrm{~A}$ a D, as parcelas que receberam ARB, no tangente a CTC quanto a V, tiveram seus valores aumentados, notadamente na camada superficial.

Queiroz et al. (2004), utilizando água residuária de suinocultura obtiveram aumento na soma de bases e na CTC do solo; entretanto, verificaram redução na saturação por bases, possivelmente em razão do aumento da concentra- ção de $\mathrm{Al}^{3+}$ no solo. Aumentos na CTC e saturação por bases também foram observados com o uso de água residuária da lavagem e despolpa dos frutos do cafeeiro conilon (Garcia, 2003) e com efluente de esgoto tratado (Fonseca et al., 2005).

Em geral, os aumentos na CTC e na saturação por bases com a aplicação de águas residuárias são atribuídos à alta concentração de íons e aos colóides orgânicos presentes nos efluentes. Neste trabalho se nota um aumento considerável
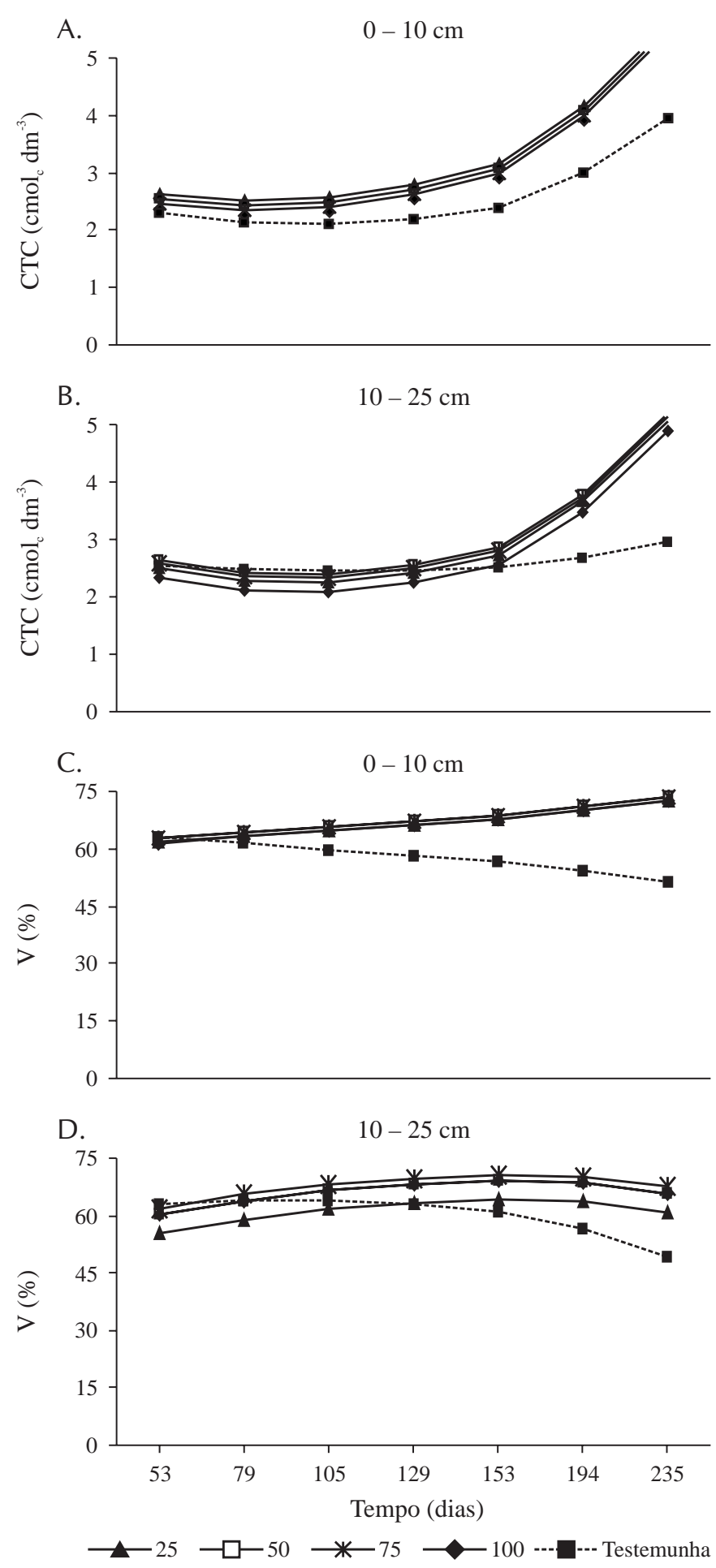

Figura 3. Valores de CTC e V estimada em função do tempo, tratamento e faixa de profundidade 
da CTC que passou, aproximadamente, de 2,5 $\mathrm{cmol}_{\mathrm{C}} \mathrm{dm}^{3}$ aos 53 dias, para 5,0 $\mathrm{cmol}_{\mathrm{c}} \mathrm{dm}^{3}$ aos 235 dias.

De acordo com a CFSEMG (1999), os valores de CTC e $\mathrm{V}$ encontrados neste trabalho podem ser caracterizados como médio e bom, respectivamente, resultados que indicam um enriquecimento do solo com o uso da ARB.

As características relacionadas à salinidade e sodicidade
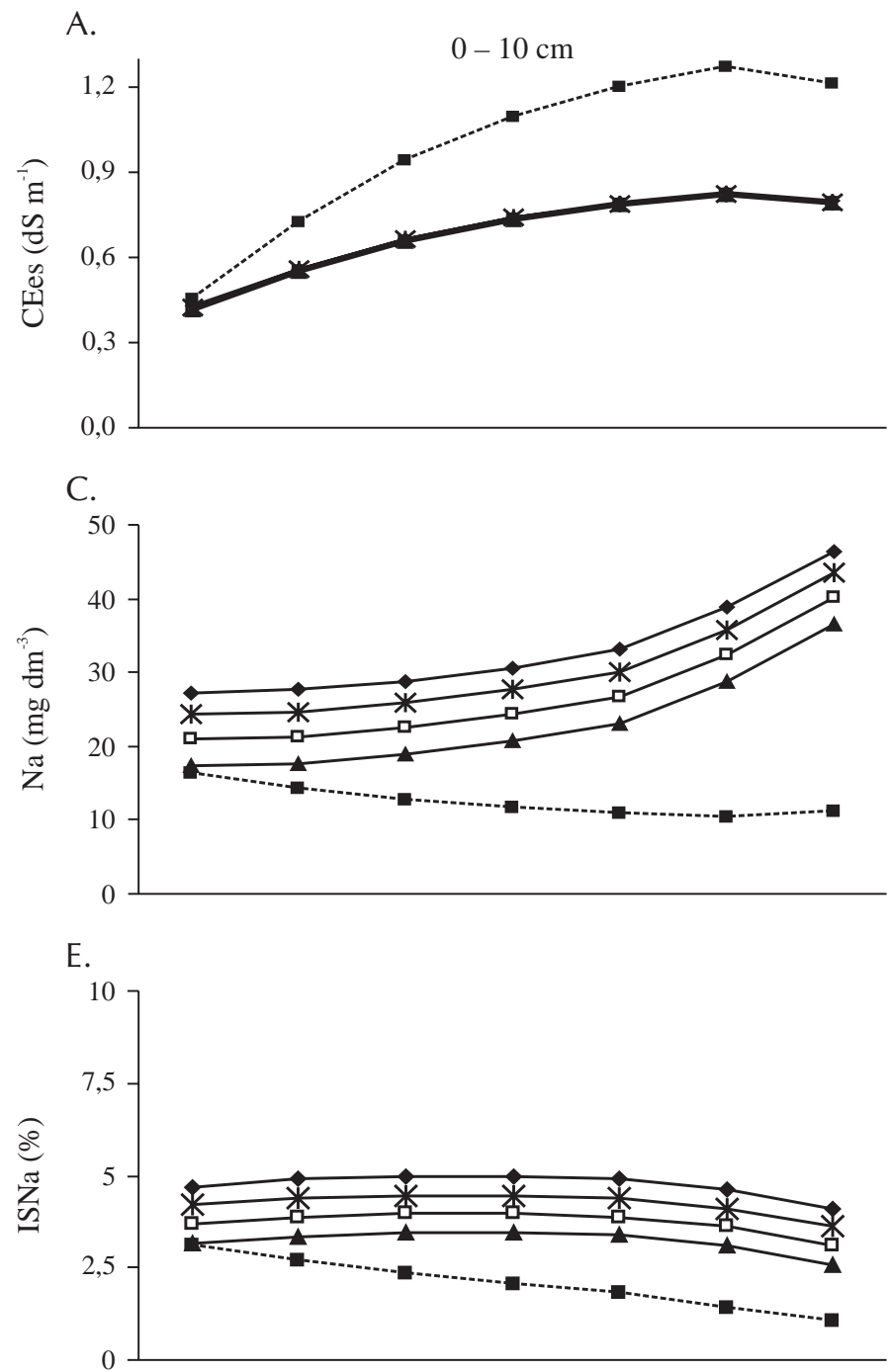

$\mathrm{G}$.

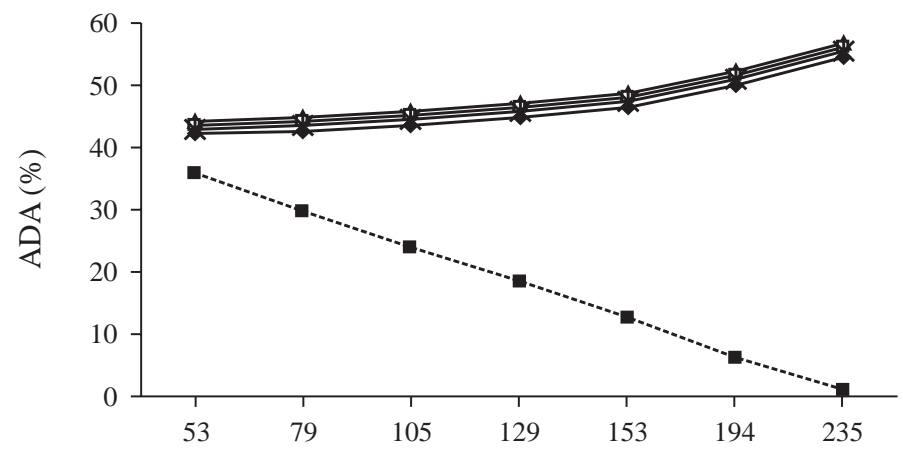

avaliadas foram a condutividade elétrica do extrato da pasta do solo saturado (CEes), concentração de $\mathrm{Na}^{+}$, índice de saturação por sódio (ISNa) e argila dispersa em água (ADA). A tendência de comportamento das referidas variáveis ao longo do tempo se encontra representada graficamente nas Figura $4 \mathrm{~A}$ a $\mathrm{H}$.

Verifica-se que os valores de CEes aumentaram em torno

B.

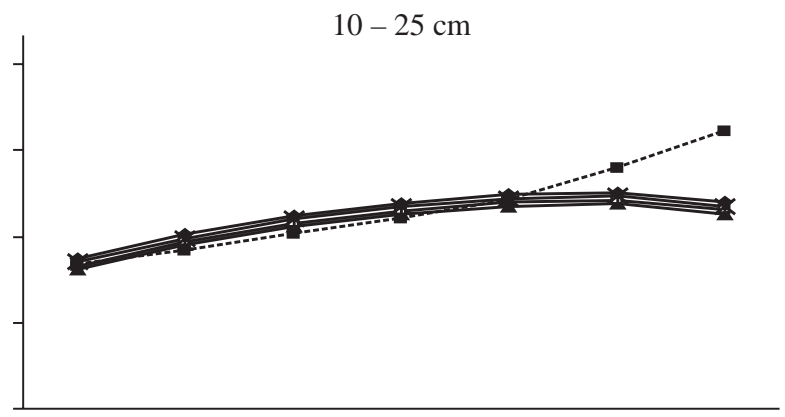

D.

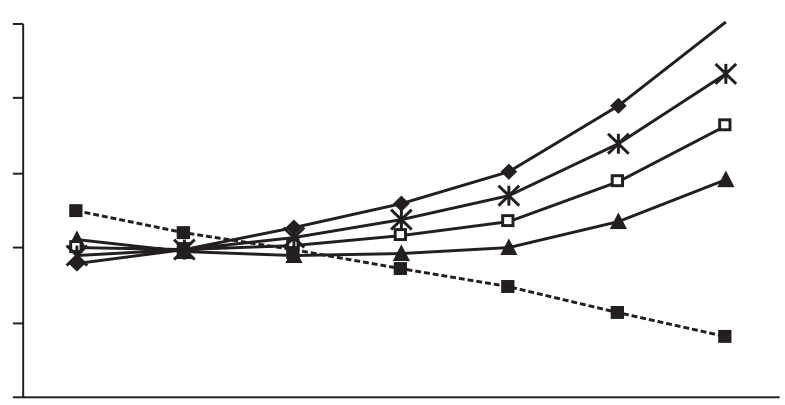

F.

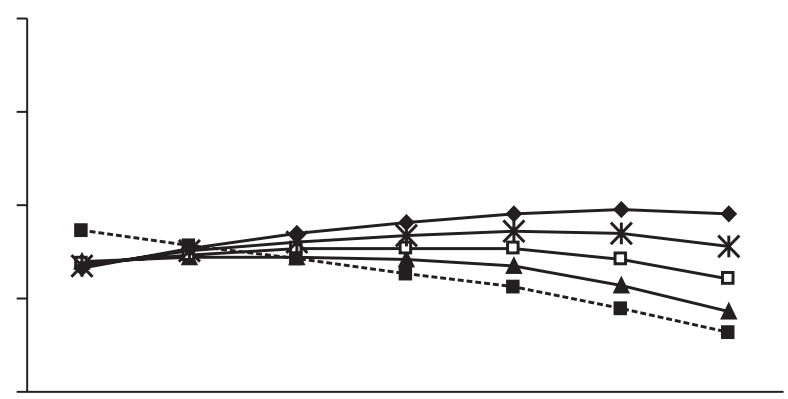

H.

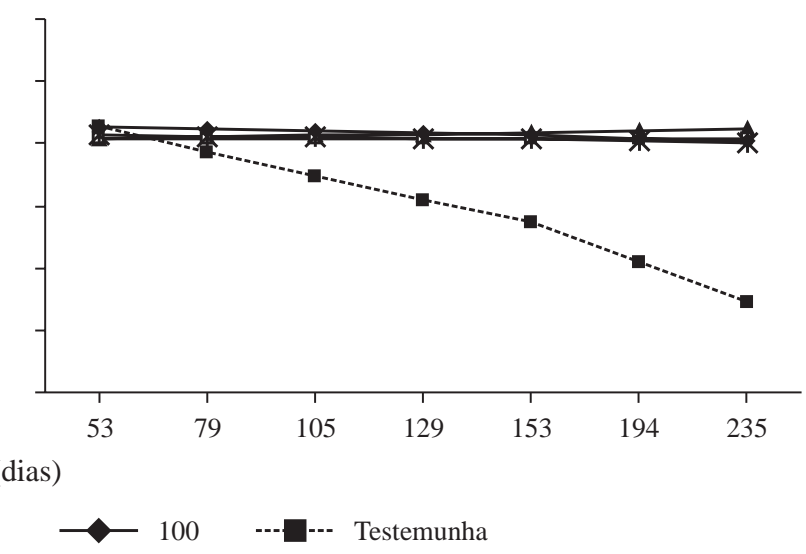

Figura 4. Valores de CEes, ISNa, ADA e concentração de $\mathrm{Na}^{+}$do solo estimadas em função do tempo, tratamento e faixa de profundidade 
de até 150 dias porém foram sempre menores que 1,5 dS m-1, valor considerado adequado para manter um rendimento potencial de $100 \%$, para a maioria das forrageiras, de acordo com Ayers \& Westcot (1999).

Salienta-se que em medições de condutividade elétrica o eletrodo só reconhece a fração ionizada da concentração total de um soluto; portanto, a concentração total dos solutos no solo na faixa de profundidade $0-10 \mathrm{~cm}$, quando fertirrigado com ARB, é maior, relativamente à CEes, em razão da complexação com a matéria orgânica.

Verifica-se também que os valores de CEes na camada superficial $(0-10 \mathrm{~cm})$ são maiores na testemunha, devido à adubação química aplicada neste tratamento; aumentos da CE da solução do solo após a aplicação de águas residuárias domésticas, têm sido relatados em áreas cultivadas com culturas anuais (Johns \& McConchie, 1994; Al-Nakshabandi et al., 1997), em pastagens (Feigin et al., 1991; Bond, 1998) e em sistemas florestais (Smith et al., 1996; Falkiner \& Smith, 1997; Speir et al., 1999); todavia, as concentrações salinas mais elevadas têm sido verificadas na camada mais superficial do solo, conforme constatado neste estudo (Cromer et al., 1984; Al-Nakshabandi et al., 1997; Speir et al., 1999).

$\mathrm{Na}$ avaliação conjunta da CEes e do ISNa, nota-se que a aplicação da ARB não causou problemas de salinidade visto que o sódio adsorvido se encontra abaixo dos limites prejudiciais. Segundo Pizarro (1990), o solo pode ser caracterizado normal, em virtude de apresentar CE $<2 \mathrm{dS} \mathrm{m}^{-1}$ e ISNa (PST) $<7 \%$.

Em geral, as concentrações de $\mathrm{Na}^{+}$e o índice de saturação por sódio (ISNa) são elevadas após a aplicação de águas residuárias, principalmente nas camadas superficiais (Cromer et al., 1984). Tem-se observado esses acréscimos em solos cultivados tanto com culturas florestais (Feigin et al., 1991; Bond, 1998) como em estudos de curta e longa duração (Quin \& Woods, 1978; Balks et al., 1998; Fonseca et al., 2005).

Altas concentrações de $\mathrm{Na}^{+}$na solução do solo em comparação com o $\mathrm{Ca}^{2+}$ e o $\mathrm{Mg}^{2+}$, podem causar deterioração da estrutura do solo, pela dispersão dos colóides e subsequente entupimento dos macroporos, causando decréscimo na permeabilidade, à água e aos gases. Nesse contexto, os acréscimos na concentração de $\mathrm{Na}^{+}$e ISNa têm sido apontados como causa (Bond, 1998) ou não (Balks et al., 1998) de alterações na condutividade hidráulica do solo, dependendo da concentração total de sais na solução. A magnitude dos impactos adversos do sódio sobre as propriedades do solo, é dependente das quantidades e frequências das precipitações ou aplicações, de forma a promover a lixiviação deste cátion (Mancino \& Pepper, 1992; Speir et al., 1999).

A variação da proporção de argila dispersa em água (ADA) de um solo ao longo do tempo, indica o grau de dispersão/floculação das partículas desse solo. De acordo com os gráficos apresentados nas Figura 4G e $\mathrm{H}$, vê-se que os valores de ADA na camada superficial ( 0 a $10 \mathrm{~cm}$ ), são maiores e com tendência de aumento com o tempo; este fato pode ser devido sobretudo ao efeito acumulativo de sódio e potás- sio nesta camada, favorecendo a dispersão, e também ao impacto das gotas de água sobre a superfície, causando desagregação das partículas do solo.

Medeiros et al. (2005) observaram redução da porcentagem de ADA utilizando água residuária de origem doméstica para fertirrigação do cafeeiro cultivado em um cambissolo; já Montes et al. (2004), trabalhando com aplicação de água residuária de origem doméstica em um argissolo, verificaram que a dispersão das argilas aumentou com o tempo até $80 \mathrm{~cm}$ de profundidade e que este aumento foi mais pronunciado na camada de 0 a $10 \mathrm{~cm}$.

\section{CONCLUSÕES}

As crescentes taxas de aplicação da ARB utilizadas tiveram as seguintes consequências nas características físicas e químicas do solo:

1. Proporcionam ligeiro aumento no $\mathrm{pH}, \mathrm{CTC}$ e saturação por bases nas camadas superficiais do solo.

2. Não causam problemas de salinidade nem de sodicidade no solo, apesar dos aumentos da concentração de sódio trocável e da saturação por sódio, com o tempo.

3. Apresentam tendência de aumentar o percentual de ADA na camada superficial, indicando que a aplicação de ARB no solo não deve ser feita de forma permanente, a fim de prevenir riscos de redução da taxa de infiltração da água no solo.

4. Não foram suficientes para elevar a concentração de fósforo disponível no solo em níveis satisfatórios, para o capim-Tifton 85 e a aveia preta.

5. Aumentam as concentrações de cálcio, magnésio e potássio trocáveis nas camadas superficiais do solo, indicando que o teor de $\mathrm{K}^{+}$no solo deve ser monitorado e usado como referência na definição de doses a serem aplicadas de ARB.

6. Não causam acúmulo de matéria orgânica no solo.

\section{AGRADECIMENTOS}

Ao CNPq, pelo apoio financeiro à pesquisa.

\section{LITERATURA CITADA}

Al-Nakshabandi, G. A.; Saqqar, M. M.; Shatanawi, M. R.; Fayyad, M.; Al-Horani, H. Some environmental problems associated with the use of treated wastewater for irrigation in Jordan. Agricultural Water Management, v.34, p.81-94, 1997.

APHA - American Public Health Association. Standart methods for the examination of water and wastewater. New York: APHA,WWA,WPCR, 19.ed., 1995. 2617p.

Artiola, J. F.; Pepper, I. L. Longterm influence of liquid sewage sludge on the organic carbon and nitrogen content of a furrowirrigated desert soil. Biology and Fertility of Soils, v.14, p.30-36, 1992. 
Ayers, R. S.; Westcot, D. W. A qualidade da água na agricultura. Campina Grande: UFPb, 1999. 153p.

Balks, M. R.; Bond, W. J.; Smith, C. J. Effects of sodium accumulation on soil physical properties under an effluent-irrigated plantation. Australian Journal of Soil Research, v.36, p.821-830, 1998.

Barton, L.; Schipper, L. A.; Barkle, G. F.; Mcleod, M.; Speir, T. W.; Taylor, M. D.; Mcgill, A. C.; Van Schaik, A. P.; Fitzgerald, N. B.; Pandey, S. P. Land application of domestic effluent onto four soil types: Plant uptake and nutrient leachig. Journal of Environmental Quality, v.34, p.635-643, 2005.

Bond, W. J. Effluent irrigation - An environmental challenge for soil science. Australian Journal of Soil Research, v.36, p.543-555, 1998.

Bouwer, H. Groundwater problems caused by irrigation with sewage effluent. Journal of Environmental Health, v.63, p.17-20. 2000.

CFSEMG - Comissão de Fertilidade do Solo do Estado de Minas Gerais. Recomendação para uso de corretivos e fertilizantes em Minas Gerais. $5^{a}$ aproximação. Viçosa, 1999. 359p.

Cromer, R. N.; Tompkins, D.; Barr, N. J.; Hopmans, P. Irrigation of monterey pines with wastewater: Effect on soil chemistry and groundwater composition. Journal of Environmental Quality, v.13, p.539-542, 1984.

EMBRAPA - Empresa Brasileira de Pesquisa Agropecuária. Centro Nacional de Pesquisa de Solos. Manual de métodos de análise de solo. 2.ed. Rio de Janeiro: Embrapa CNPS, 1997. 212p. Documentos, 1.

Falkiner, R. A.; Smith, C. J. Changes in soil chemistry in effluent-irrigated Pinus radiata and Eucalyptus grandis. Australian Journal of Soil Research, v.35, p.131-147, 1997.

Feigin, A.; Ravina, I.; Shalhevet, J. Irrigation with treated sewage effluent: Management for environmental protection. Berlin: Springer-Verlag, 1991. 224p.

Fonseca, A. F. ; Herpin, U; Paula, A. M.; Victoria, R. L.; Melfi, A. J. Agricultural use of treated sewage effluents: Agronomic and environmental implications and perspectives for Brazil. Scientia Agricola, v. 64, n.2, p.194-209, 2007a.

Fonseca, A. F.; Melfi, A. J.; Monteiro, F. A.; Montes, C. R.; Almeida, V. V.; Herpin, U. Treated sewage effluent as a source of water and nitrogen for Tifton 85 bermudagrass. Agricultural Water Management, v.87, p.328-336, 2007b.

Fonseca, A. F.; Melfi, A. J.; Montes, C. R. Maize growth and changes in soil fertility after irrigation with treated sewage effluent. II. Soil acidity, exchangeable cations, and sulfur, boron and heavy metals availability. Communications in Soil Science and Plant Analysis, v.36, p.1983-2003, 2005.

Friedel, J. K.; Langer, T.; Siebe, C.; Stahr, K. Effects of longterm waste water irrigation on soil organic matter, soil microbial biomass and its activities in central Mexico. Biology and Fertility of Soils, v.31, p.414-421, 2000.

Garcia, G. de O. Alterações químicas, físicas e mobilidade dos íons no soldecorrentes da aplicação de água residuária da lavagem e despolpa de frutos do cafeeiro conilon. Viçosa: UFV, 2003. 101p. Dissertação Mestrado
Johns, G. G.; McConchie, D. M. Irrigation of bananas with secondary treated sewage effluent. II. Effect on plant nutrients, additional elements and pesticide residues in plants, soil and leachate using drainage lysimeters. Australian Journal of Agricultural Research, v.45, p.1619-1638, 1994.

Mancino, C. F.; Pepper, I. L. Irrigation of turfgrass with secondary sewage effluent: soil quality. Agronomy Journal, v.84, p.650-654, 1992.

Matos, A. T. Tratamento de resíduos na pós-colheita do café. In: Borém, F. M. (Org.). Pós-colheita do café. 1.ed. Lavras-MG: UFLA, 2008. Cap. 6, p.159-201.

Matos, A. T.; Pinto, A. B,; Pereira, O. G.; Barros, F. M. Alterações nos atributos químicos do solo de rampas utilizadas no tratamento de águas residuárias. Revista Brasileira de Engenharia Agrícola e Ambiental, v.9, n.3, p.406-412, 2005.

Medeiros, S. S.; Soares, A. A.; Ferreira, P. A.; Matos, A. T.; Souza, J. A. A. Utilização de água residuária de origem doméstica na agricultura: Estudo das alterações químicas do solo. Revista Brasileira de Engenharia Agrícola e Ambiental, v.9, n.4, p.603-612, 2005.

Mohammad, M. J.; Mazahreh, N. Changes in soil fertility parameters in response to irrigation of forage crops with secondary treated wastewater. Communications in Soil Science and Plant Analysis, v.34, p.1281-1294, 2003.

Mônaco, P. A. V.; Matos, A. T.; Martinez, H. E. T.; Ferreira, P. A.; Ramos, M. M. Avaliação do estado nutricional do cafeeiro após fertirrigação com águas residuárias da lavagem e descascamento de seus frutos. Engenharia na Agricultura, v.15, n.4, p.392-394, 2007.

Montes, C. R.; Fonseca, A. F.; Melfi, A. J.; Santos, A. P. R.; Gloaguen, T.; Forti, M. C.; Pivelli, R. Agricultural use of stabilization pond effluent: a case study in the city of Lins (SP, Brazil). In: International Meeting of International Humic Substances Society, 12, 2004, São Pedro. Resumos... São Pedro: EMBRAPA, 2004. v.1. p.732-734.

Myers, R. J. K.; Campbell, C. A.; Weier, K. L. Quantitative relationship between net nitrogen mineralization and moisture content of soils. Canadian Journal of Soil Science, v.62, p.111-124, 1982.

Pizarro, F. Riegos localizados de alta frecuencia. 2.ed. Madrid: Ediciones Mundi-Prensa, 1990. 471p.

Queiroz, F. M.; Matos, A. T.; Pereira, O. G.; Oliveira, R. A. Características químicas de solo submetido ao tratamento com esterco líquido de suínos e cultivado com gramíneas forrageiras. Ciência Rural, v.34, n.05, p.1487-1492, 2004.

Quin, B. F.; Woods, P. H. Surface irrigation of pasture with treated sewage effluent. I. Nutrient status of soil and pastures. New Zealand Journal of Agricultural Research, v.21, p.419-426, 1978.

Ramirez-Fuentes, E.; Lucho-Constantino, C; Escamilla-Silva, E.; Dendooven, L. Characteristics, and carbon and nitrogen dynamics in soil irrigated with wastewater for different lengths of time. Bioresource Technology, v.85, p.179-187, 2002.

Smith, C. J.; Hopmans, P.; Cook, F. J. Accumulation of Cr, Pb, $\mathrm{Cu}, \mathrm{Ni}, \mathrm{Zn}$ and $\mathrm{Cd}$ in soil following irrigation with treated urban effluent in Australia. Environmental Pollution, v.94, p.317-323, 1996. 
Speir, T.W.; Schaik, A. P. Van; Kettles, H. A.; Vicent, K. W.; Campbell, D. J. Soil and stream-water impacts of sewage effluent irrigation onto steeply sloping land. Journal of Environmental Quality, v.28, p.1105-1114, 1999.

Stanford, G.; Smith, S. J. Nitrogen mineralization potentials of soils. Soil Science Society of America Proceedings, v.36, p.465-472, 1972.

Stevenson, F. J. Cycles of soil: carbon, nitrogen, phosphorus, sulfur, micronutrients. New York: John Wiley, 1986. 380p.
Stewart, H. T. L.; Hopmans, P.; Flinn, D. W. Nutrient accumulation in trees and soil following irrigation with municipal effluent in Australia. Environmental Pollution, v.63, p.155-177, 1990.

Wang, Z.; Chang, A. C.; Wu, L.; Crowley, D. Assessing the soil quality of longterm reclaimed wastewater-irrigated cropland. Geoderma, v.114, p.261-278, 2003.

Yan, F.; Schubert, S.; Mengel, K. Soil pH increase due to biological descarboxilation of organic anions. Soil Biology \& Biochemistry, v.28, p.617-624, 1996. 